(c) 2010 IEEE. Personal use of this material is permitted. Permission from IEEE must be obtained for all other uses, in any current or future media, including reprinting/republishing this material for advertising or promotional purposes, creating new collective works, for resale or redistribution to servers or lists, or reuse of any copyrighted component of this work in other works. 


\title{
The Critical Success Factors for Implementation of CRM and Knowledge Management in a Work Setting
}

\author{
Alireza Faed, Pedram Radmand, Alex Talevski \\ DEBII, CBS, Curtin University of Technology \\ Perth, Australia \\ alireza.faed@postgrad.curtin.edu.au,pedram.radmand@postgrad.curtin.edu.au, \\ Alex.Talevski@cbs.curtin.edu.au
}

\begin{abstract}
Customer Relationship Management is the most vigorous tools in our era and is the integration of trust, business and technology to gratify the requirements of the clients. CRM is a strategy of dealing with people, technology and process and need to be implemented precisely. CRM is the most outstanding business strategy that consolidates internal procedures and externals to generate and convey value to the spotted customers and CRM can easily neutralize competitive perils; provide a good source of roadmap for the company and customers. Moreover it may clarify the potential pitfalls in creating success for the company. CRM involves validating and evaluating critical success factors, which cover the three perspectives of CRM as the theoretical base, and which constitute a guide for companies in the implementation of the applications. Due to this, the desired benefits have intensified customer satisfaction and maintenance, by generating personalized products and value-added services. In this paper, the author investigates the factors that can positively leverage the implementation and use of CRM and creates differentiation among these factors and knowledge management factors. What is more, the paper aims at determining technical feature between CRM and knowledge management and managed to compare $\mathrm{KM}$ with CRM successfully.
\end{abstract}

Key word: Customer Relationship Management, Knowledge Management

\section{INTRODUCTION}

In the present business ecosystem, the battle to win customers is growing stronger, due to an increasingly aggressive competition. The company that enters to compete in the new market must evaluate that market because the business has to adapt to constant change and technological evolution; hence the CRM concept has evolved in such a way as to become extremely important to improve the customer lifetime value. In the implementation of CRM, due to the different culture and business process in organizations, there is no predefined model. Therefore, it is of utmost importance to consider that CRM is not a magic solution to solve the organization's problems, but there should be an accurate study to examine the impacts and benefits of CRM in the organization. The implementation of CRM as a strategy requires hard work for it to be successful [17]. In fact, when the organization embarks on a transition to the customer-centric model, the development of capability to acquire necessary resources, appropriate knowledge and tools is mandatory to meet the customers' needs. However, this cannot be applied in many organizations especially financial ones, which are product-oriented instead of customer-centric and therefore inconsistent with customers' expectations. This means that these organizations determine the processes in terms of product lines and not customer lines because these companies have a legacy of customers who become unprofitable [11], [12], [19], and [28].

\section{LITERATURE REVIEW OF CRM IMPLEMENTATION}

Strategic and technological issues are all outstanding in achieving CRM triumph. The company needs to expand a vivid business case and performance framework to obtain a successful CRM initiative. These companies have been concentrated on projects to confine their spectrum towards their goals. CRM implementation is focused on functional areas such as customer support, services, marketing and sales. The CRM lifecycle comprises of three stages: integration, analysis and action. A centralized source of all pertinent customer data is achieved through the integration stage. The second stage which is, analysis, enables the effective management of the customer relationship and analyses customer behaviors in terms of customer-buying patterns and recognizes casual customer bonds, and the final stage, action, carries out the strategic decision. As a matter of fact, the aim of CRM cycle is to generate the organization and the customer-facing employees with a single and accomplish the view of customers in every point of contact and all through communications. In addition, the CRM phase provides the customer with a single and complete prospective of the company and its extended channel [26]. During the analysis stage, the business procedure and organizational structure are gained through the acquiring of customer understanding. It should be clarified that, due to the complicatedness of various operations in administering customer bonds, a successful CRM implementation needs abundant organizational 
transition. By entrenching new approaches for managing customers, different facets of the company, such as business processes, strategies, top management support, and employee training will be deployed [17].

\section{A. Customer Relationship Management}

Customer relationship management is a term employed to the implementation of some procedures within a company to arrange its customers through the CRM software that is used to support the procedures. This information will be accessible to employees of the organization in atypical departments to store and enter customer information, whether current or anticipated (Contributors 2008. "CRM is a process in which manages all factors of the relationship, a company has with its customers and potential customers" (Blackwell 2007, p.54). As Levitt [27] suggested, the goal of business is to create and maintain customers. After more than four decades, it appears to be the requirement to maintain a lasting relationship with clients that is very significant (Levitt 1960). The companies have realized that they can obtain a better relationship with their customers and endure in the today circumstances through the implementation of CRM. In a CRM strategy, it is vivid that all stages of the organization be deployed toward favoring a proper bond with the client [17]. Based on Giga survey, companies depreciate the convolution of CRM; thus, they invest inadequately in the supplying of CRM software [17]. The CRM business strategy involves marketing, operations, sales, customer service, research and development (R\&D) and finance, as well as IT to intensify the profitability of customer interactions. Moreover, CRM progress beyond other tools and methods to capture and compass operational, analytical and collaborative factors (Bull 2003). While CRM aims at satisfying clients and creates lucrative business, therefore the analysis of the relationship processes with the customers is absolutely critical. These processes encompass marketing, sales and services. Theses processes are well known as prevalent processes and happen repeatedly in the CRM system. Marketing, sales and service procedures are cultivated and adjusted to the new demands of the market throughout the time. The development of these procedures is moved toward the satisfaction of customers and creation of satisfaction for them (Bull 2003). In accordance with Light [17] many organizations implement CRM systems in functional repositories such as sales, marketing and service through a call center (Light 2001). This states that CRM evolves from business procedures, relationship marketing and efficient management of customer relationships [17].

\section{DIFFERENT ASPECTS OF CRM}

\section{A. An action model for CRM}

A procedure to actualize and implement CRM project in the company is required. This includes major steps to be taken. It should be mainly focused on the requirements of the consumer alone to assist the assurance of the procedure.

1. Analysis for replacement: this applies on the requirements of the procedure.

1.1. Initialization. It concentrates on the initial implementation objectives. There must be various stages for initialization which will be described in the following section:

1.1.1. Strategic Planning: Used for improving the view of implementation procedure. Significant elements that generate the success or failure of implementation in CRM procedure are securing managerial support and describing the strategies need to be formulated [27]. In defining the aim of implementation, it should be separated in terms of standard, strategic and operative knowledge aims. The standard aims relate to the fundamental stage of vision that is pertinent to the policy of the company and based on its organizational culture functioning as critical knowledge areas. In terms of knowledge objectives, the company's lasting targets must be corresponded as a model for enhancement process of the company. The operative strategy formulates the long-terms measures for recognizing the standard aims and operative knowledge goals of the organization. It is the basis of recognizing strategy within the context of routine activities in the company [27].

1.1.2. Business Case: it creates the implementation procedure with the basic draft of the process model that involves the financial plan and initial approximate of the cost-benefit bond. The business case outlines the vision and initial strategic aim. This information will be beneficial for customers that are engaged in budget making of the process [27]).

1.1.3. Steering Group: It avoids the distribution job that does not clarify the accountability clearly [27]. It defines a methodology for designing jobs that customers are tempted to carry out efficiently.

1.2. Requirement analysis: it illustrates the current circumstance of the company. The requirements analysis should be performed in relationship with employees to generate positive attitudes and reduce reactance, resistance to change and potential conflict from the users [27].

1.2.1. Reactance: The emotional reaction that generates to give feedback concerning any threatening behavioral independence. Feedbacks which are positive or negative normally create with a major change in an attitude or while a customer is under pressure to admit a certain attitude. In terms of the psychological aspect, having feedback commences from human nature. As an example, admitting that customers are aware of the advantage of change, they are unlikely to admit to adapt themselves to the new atmosphere [22].

1.2.2. Resistance to Change: Each system as an entity has a resistance to change. Cooperation, like other social 
structure gives a positive feedback to behave towards change [22].

1.2.3. Conflict: it takes place in environments that decisions are made by more than one manager or the person who is in charge. While analyzing, it is really significant to estimate the cause of conflict that may be caused by homogeneity and heterogeneity of groups [22].

1.2.4. Perception: It is one of the most outstanding elements that a triumph implementation depends on. Because of the various prospective of customers, each customer apprehends the advantages of implementation and innovation differently since they define information based on their pervious experience [22].

2. Become aware of the implementation. This stage emphasizes on the possible conception.

2.1. Conception: Concentrates on detailed work on how to measure the concept, project management and acceptance concepts [27].

2.1.1. Measures the concepts: Defines the individual measures description in detail. It forms at the starting point of project management planning [27].

2.2.2. Project Management Concept: Describes work package and time plan to improve framework in implementation [27].

2.2.3. Acceptance Concept or Acceptance model: Measures the likelihood of acceptance and is the act of accepting what is proposed with consent and satisfaction. Based on [27], organization, technology, participation, and qualification are elements that can be utilized to enhance motivation in an organization to ensure the acceptance of measures [27].

2.2. Realization: Is composed of the facets of piloting, and formative evaluation [27].

2.2.1. Pilot Project: Is one of the key factors that identify potential issues. Besides, it tries not to leave the project in future dangers. While choosing samples, it is not reasonable to engage somebody who has a negative behavior toward the process, and in big projects they recommend to motivate everyone. In the pilot test, the accountability of each individual is vital [27].

2.2.2. Formative Evaluation: It is accomplished to identify the problem areas within the project. This measure should be integrated for enhancement of the project. During the rollout phase, the outcomes of the pilot project's formative assessment form the basic arrangement and modification of the major implementation [27].
2.2.3. Rollout: The outcomes from the formative assessment create the basis for the rollout procedure. It is important for the managers to have a proper communication in the project to discard any uncertainties [27].

3. Monitoring the Implementation: Comprehensive assessment of the project is mandatory to ensure constant enhancement of the process to fulfill the needs of the clients. A quality analysis and a cost-benefit analysis should be conducted to gain an effective result [27].

3.1. Quality Analysis: The analysis must be focused on the final expected aims Moreover, it need to be formulated in the Business Case [27].

3.2. Effectiveness Analysis: This step tests the measurements of the reaction in target group and directly addressed by survey. During this stage, it is important to concentrate on standards, strategic and operating goals. [27].

3.3. Cost-Benefit Analysis: it will be conducted according to cost estimating and the proof of described achievement. This analysis records the performance as a reference for the future to further enhancement [27].

\section{CRM GOALS}

The main goal CRM is eagerness in implementing customer-oriented strategies producing new facets of mutual interactivity between customer and the company [5], [9]. In addition, another objective of CRM is to enhance the services created to the customers and to better utilize the information in the system for targeted marketing. What is more, the fundamental aim of CRM is to intensify profitability through productive and optimized bond with customers [18]. Acquiring CRM aims, will be based on CRM implementation process, critical success factors along with process, technology and human factor that will be defined below [28].

\section{TECHNOLOGY AND PROCEDURE ELEMENTS}

Today, Technology has become as a new paradigm in doing business and being successful in it. However, adapting to the new paradigm is very demanding and cost a fortune for companies. Nearly, most of the companies are struggling to identify clients' needs and consolidate the applications to gather all client information. According to [17], technology ameliorates the interaction the company and clients and is the key to electronic business and CRM.

Integration: Customer behaviors must be analyzed in terms of customer-buying patterns and delivers casual relationships to gain a successful CRM implementation. Hence, the consolidation of systems is significant in a 
client-relationship. In addition, it is probable to evaluate the information of the client which has been utilized by various segments of system such as sales and services and marketing [14].

Software for CRM: Software must be authentic and its preference for the customers is vital and the selection of that is significant in implementation a successful CRM because this software consists of many multi-functional solutions that can sort out the information management of clients as well as the automation interaction processes of clients. [14]. While this argument is a valid one, poor quality software can deteriorate the implementation attempt [12]. CRM as a strategy is a comprehensive configuration of business and technological factors.

\section{HUMAN FACTORS}

While both business processes and technology are centred to a successful CRM strategy and system, it is the end user who attempts to generate and enhance the customer relationship by responding to the company. There are several rules encompassing management and employees that conduct to a successful CRM implementation. As the key factor in CRM is sorting out the relationships with the customers, there must be a way, which counts on the fact that involves parties including: a provider and a purchaser, to sort out the relationship with the customer [17]. However, the human side of engineering has disregarded in CRM implementation, but it needs to be considered that objections and some disagreements that arise in business process are dealt with by employees' intervention and top management. They may leverage the CRM innovations and decline impediment to change through their motivation. Thus, CRM initiatives require vision and generate modification for the company. Companies that cannot completely understand the aim of change may encounter with some failure in implementation of successful CRM, to this aim, effective knowledge transfer and knowledge sharing would change the role of the employee from passive acceptance to active involvement [28].

Customer contact manager: It is significant for a successful CRM implementation in a company. Collecting the contact manager would be easier through Call Centre because this technology provides a facility to route and administer telephone calls to assist receptionist. What is more, it provides customer details to help desk personnel through their call. Interactive voice response, which is based on a menu system, allows the users to communicate with other technologies to collect some information and execute differentiated functions [12]. However, there is a problem in call centres that leads to inefficiency which is, when customer information is spread out within an organization in different systems, it would be very difficult for the operator to access them in a timely. The modern call centres are comprised of traditional technology, and the new internet enhancements have become widespread among companies.

Customer Service: The advent of this service goes back to the last decade. Companies have identified that the development of areas which specialize corresponding to customer-based issues would expand customer satisfaction with the quality of services [17]. Consideration of this element during the implementation of CRM would be considerable in terms of choosing the proper CRM software.

Organizational behaviour change: Transition from a product-oriented to customer-oriented attitude within organization requires a change in organizational attitude and a change in culture within the organizations staff. One of the effective ways to change the culture in the organization is to continually provide training of the employees as to what is required of them in the future [25]. Furthermore, low quality services in a company such as shortage of expertise, presence of careless staff, rude employees, and slow responses create low service quality and lead to customers' disloyalty.

Organizational culture management: It is something that needs to be changed after a period in a company to improve the culture of the company in CRM implementation, knowing that changing a culture in a work setting may take years. Organizational culture could be a reason why CRM initiatives in some companies fail [25].

Staff and Managerial commitment: At the managerial stage the efficient and charismatic leadership is vital in terms of the degree of the commitment. This implies the role of those who are in charge high position. They need to monitor CRM procedures in the company and make them aware of the benefit and results of the CRM strategies. Top management must patronize the CRM system and promote commitment and motivation throughout organization. Middle managers and supervisors leverage the employees, who are pertinent to the customer, for this reason they have a significant role in CRM implementation.

Communication and follow-up: In CRM implementation, both creating new means of communication, performing them and follow up which is reviewing all techniques and promoting them, acquiring customers and keep providing proper relationship with them are really important [17].

Effective leadership: As discussed before, CRM involves procedures of comprehensive change via introduction of a new technology in the organization. To this aim, efficient management is vital in CRM implementation. The human factor is important, whether employees or customers, and the bond between them can determine the effectiveness of 
business strategy; so it is important to motivate the employees, who are engaged with strategy. In addition, as CRM has been included with the business procedure and initiation of new technology, the efficient leadership is vital for implementation of CRM because the external environments of a company which is the best place to describe the strategy of CRM projects is monitored by a leader. In addition, they are authorized to monitor the expenses, setting and monitoring performance, and empowering and motivating key employees [19]. Managing support and leadership: Without the commitment and support management, even the most brilliant CRM deployment and implementation initiatives would not be successful [13]. In fact, implementation of CRM needs to roll out an enterprise-wide program of change management to ease the transformation of the organizational culture into a customer-centric one. Rigby (2002) mentioned that, a lack of adequate change management leads to CRM failure [20]. The company has the knowledge, skills, resources, tools, management processes and systems, is directly related to CRM success. Also the success depends on the leadership team taking ownership of the CRM strategy [20]. The organizations' employees should be trained to work with the software and they must be familiar with all existing features of software to serve the clients. Training increases the performance of employees to customers' satisfaction and companies' profits as well [12], [11].

\section{OVERALL CRM IMPLEMENTATION STEPS:}

The following steps are noticed for CRM implementation

1. Identify customers and creating a proper relationship with them.

2. Identify which types of customers are most profitable, whether by sales or profit contribution.

3. Attempt to recognize the behavior of the most profitable customers and find out how to motivate the behavior of the most profitable customers and cross-sell other products to customers.

4. Keep the contact with the most profitable customers.

5. Manage activities of the company that satisfy or maybe lead to the gratification of the most profitable customers and make them become a potential and loyal customer for the company.

However, during the implementation there are some issues that lead to failure to reach a successful CRM implementation.

\section{CRM IMPLEMENTATION ISSUES}

A. Shortage of holistic approach found by researchers
It is vital as it locates CRM at the centre of the company with a customer-oriented process and integration of CRM system. A holistic approach helps the organization to effectively maintain the growth of customers through channels of communication [14], [21]. Ultimately, a holistic approach should have taken to explore the factors that affect CRM implementation.

Outsourcing: This strategy is considered, based on the business strategy or lack of resources in the company. The outsourcing creates some issues in terms of consolidation and effective collaboration. However, CRM is wellknown to be facilitating the outsourcing of more business operations directly to the customers [15].

Lack of ability to deliver strategy: Another important factor in implementation of CRM that may cause some problems is the lack of ability to deliver the strategy successfully. CRM strategies should deliver positive outcomes. According to Newell (2000), rather than being customer focus, strategy should be customer operational. If the since CRM strategy is struggling to influence the profitability, then, it is sensible that after a reasonable period of time the project will be considered a failure. In this situation the organization should try to adopt an alternate strategy, although sometimes it is very hard for those organizations that are in this position to recover. On the other hand, if CRM increases profitability, the company clearly would be on the right track. In this way, companies should be conservative and devote enough resources and time to CRM to achieve to an productive CRM strategy (Bull 2003).

\section{B. Information systems (IS)}

One of the main issues considering CRM is that it is considered as software instead of a strategy. However, it should be mentioned that the software is part of the CRM system as a component of Information System. The software facet of the system has become very significant because of its capability to perform a solution that lets the management to facilitate information between various sorts of the systems (Turban, Aronson and Liang 2006).

\section{B. Sales force automation (SFA)}

One of the main problems of CRM-oriented software, especially in regarding the area of sales, is that the software is learnt through time. Due to this, for implementation to be a solution, a radical change must not be performed where people work. The only way of implementing a solution of this kind that brings benefits to the company, is to correctly assess and evaluate each element, and form a holistic viewpoint within the CRM strategy to align people, processes and technology. Companies actualize particular products and usually market them, established on their own culture and practices. For example, the study accomplished by Forsyth (2001) illustrated that the most of the problems 
that cause failure to reach a successful CRM are listed below (Forsyth 2001): 1-Organizational change (29\%). 2Company policies/inertia (22\%). 3-Little understanding of CRM (20\%). 4-Poor CRM skills (6\%).

\section{THE ORGANIZATIONAL CHALLENGE} OF CRM

Functional silos: Due to functional and divisional 'silos' within organizations, innovation has not become embedded as a key driver and growth profitability because innovation has been limited by these functional and divisional silos. As an example, the responsibly for some initiatives has been restricted by Research and Development department [21]. Companies that plan to implement CRM should redefine the existing functional 'silos' and create a structure to focus on the entire scope and life cycle of customer relationship within organizations (Kennedy 2007). In fact, for successful implementation of CRM, the entire organization should be realigned to focus on the customer [21].It should be mentioned that, multi-channel management is one of the most important factors in a successful CRM strategy and lack of coordination can result in failure, by delivering an incomplete and distorted view of the customers (Crosby 2002).

New customers: Relationship customers are also more cost effective than new customers because new customers are not familiar with the products or services and require a great deal of effort to persuade them to buy a company's products or services. In other words, it would be beneficial to distinguish the customers in three categories such as top, middle and lower groups. The top group consists of customers with excellent loyalty and high profitability. This group is vital for the organization so that in order for them to be retained, the company should offer the best service to satisfy them. The middle group consists of customers providing good profits, not as well as the top category, but there is a good potential to increase their loyalty and growth. Through the CRM, there is good opportunity to target this middle group as they are the greatest source of potential growth. The lower group, relational customers are those who are only slightly profitable. Although, there may be some potential for growth in targeting such members via CRM, the expense and effort are required to target them may hinder the effectiveness of servicing existing customers in the top and middle group (Bull 2003). It is challenging to align the systems in conforming to the strategy, where the client is the core of system (Turban 2006).

Knowledge management and the differentiation of that with CRM

Customer-focus knowledge management requires a positive attitude to extract value for the organization by managing CRM over time. The organization, in order to really manage customer relationships, should first, develop a culture, motivating employees at all levels towards learning and facilitating them in capturing, selecting, using, and sharing knowledge by providing the means and the technology required to do so [24]. Knowledge is a vast and summarized notion which is described epistemological debate in western philosophy [3]. Knowledge management is concentrated on knowledge flow and the procedure of creation, sharing and distribution of knowledge [3]. To have a favorable Knowledge management implementation in an organization, parity among three components, knowledge management of the organization, people and technology and process should be considered. Meanwhile, this paper showed that to achieve the CRM aims, based on the insights gained from CRM implementation process, three significant factors such as process, technology and people should be taken into consideration. Moreover, both CRM and $\mathrm{KM}$ implementation have the same procedure and different and similar factors for implementation. The procedure, for both includes three phases such as change analysis, realizing and implementing and monitoring and implementation. As can be seen, there are some similarities and differences between success factors for the implementation of CRM and KM. It should be mentioned that, implementation of CRM is more likely to be technological while, implementation of $\mathrm{KM}$ is more organizational. Based on this characteristic, the organizational factors should be considered in the implementation of $\mathrm{KM}$ in an organization. In fact, a successful implementation of $\mathrm{KM}$ in an organization provides an appropriate place and some facilities for the organization to implement a successful CRM. In other words, a successful implementation of KM leads to bring the organization to state of readiness for the implementation of CRM. Both CRM and KM implementation there needs to be more attention paid to the importance of human factors. It means to be oriented towards employees and their role in the organization, therewith avoiding reactance towards and increasing acceptance of $\mathrm{KM}$ and CRM implementation effort among employees.

The process factor in KM implementation is to identify, verify, capture, disseminate and use knowledge in the organization while this factor in CRM includes marketing, sales and services to achieve a business process strategy aims and a long-term relationship with the customers. However, it should be mentioned that, these factors are not considered as critical success factors in CRM implementation. In a word, KM embraces information and knowledge, while CRM encompasses functions. As it can be seen, the process factor is similar in both CRM and $\mathrm{KM}$, but it applies in different aspect during the implementation in the organization. In addition, there are many outstanding overlaps between KM and CRM. KM should contribute to marketing communication and find prevalent channels to create response-promoting content. 
Additionally, marketing research should be a major contributor to $\mathrm{KM}$ and deliver insights on customer demographics and behaviors of value in all customers' transaction and relationship strategies and tactics. Another noteworthy factor that is extremely important in both $\mathrm{CRM}$ and $\mathrm{KM}$ is aspect of technology factor, because Information Technology infrastructure allows easy communication and collaboration between employees and it enables the organization to easily communicate with customers and suppliers and collect knowledge about the business partners, thus, it would assist in the implementation of KM and CRM. Furthermore, information system consolidation is vital in $\mathrm{KM}$ implementation for dissemination of information and knowledge, while this factor also is extremely important in a client-relationship in CRM implementation. Senior management and employee liability are important for both CRM and KM as human factors because without them CRM and KM would not be successful. Managing a holistic approach and definition of the objective of projects should be considered for both implementations, whether CRM or KM. A holistic approach is appointed at the centre of the organization with a customer-focused process and help acquiring knowledge that fulfils the customers' needs.

A. Comparing the technical feature between CRM and knowledge management

\begin{tabular}{|l|l|}
\hline \multicolumn{1}{|c|}{$\begin{array}{c}\text { Knowledge } \\
\text { Management }\end{array}$} & \multicolumn{1}{c|}{ CRM } \\
\hline Access to information [3] & \multicolumn{1}{c|}{$\begin{array}{l}\text { Evaluate customers; } \\
\text { carry out customer } \\
\text { satisfaction research } \\
\text { [24] }\end{array}$} \\
\hline $\begin{array}{l}\text { Capability and potential } \\
\text { to leverage action [3] }\end{array}$ & $\begin{array}{l}\text { Accepting that CRM can } \\
\text { bring about more touch- } \\
\text { points to the company but it } \\
\text { does not always intensify } \\
\text { the sale in the company [4], } \\
\text { however, it will lead the } \\
\text { company to leverage actions }\end{array}$ \\
\hline $\begin{array}{l}\text { Support development of } \\
\text { individual and } \\
\text { organizational } \\
\text { competencies [3] }\end{array}$ & $\begin{array}{l}\text { Preparing an effective CRM } \\
\text { system may create a good } \\
\text { environment for client's } \\
\text { prioritization. [5] }\end{array}$ \\
\hline $\begin{array}{l}\text { Gathering, storing and } \\
\text { transferring knowledge } \\
\text { [3] }\end{array}$ & $\begin{array}{l}\text { Acquiring, retaining and } \\
\text { building long term } \\
\text { relationship with customers } \\
\text { [5] }\end{array}$ \\
\hline Efficiency gains, cost & Clients for share \\
\hline
\end{tabular}

\begin{tabular}{|c|c|}
\hline $\begin{array}{l}\text { saving, Collaboration } \\
\text { with } \\
\text { and avoidance of re- } \\
\text { inventing } \\
\text { the wheel [6] }\end{array}$ & $\begin{array}{l}\text { maintaining company's } \\
\text { customer value generation } \\
\text { [6] }\end{array}$ \\
\hline $\begin{array}{l}\text { Performance against } \\
\text { budget [6] }\end{array}$ & $\begin{array}{l}\text { Performance considering } \\
\text { customer satisfaction and } \\
\text { loyalty [6] }\end{array}$ \\
\hline Customer satisfaction [6] & Customer retention [6] \\
\hline $\begin{array}{l}\text { Recipient of incentives } \\
\text { are employees [6] }\end{array}$ & Customers [6] \\
\hline $\begin{array}{l}\text { Role of customers is } \\
\text { passive [6] }\end{array}$ & $\begin{array}{l}\text { Captive, linked to product/ } \\
\text { service by loyalty plans [6] }\end{array}$ \\
\hline $\begin{array}{l}\text { Unlock and integrate, } \\
\text { employees' knowledge } \\
\text { about customers, sales } \\
\text { processes, and R\&D [6] }\end{array}$ & $\begin{array}{l}\text { Data mining knowledge } \\
\text { about the customers } \\
\text { behavior [6] }\end{array}$ \\
\hline $\begin{array}{l}\text { Encourage employees to } \\
\text { share their knowledge } \\
\text { with their colleagues [6] }\end{array}$ & $\begin{array}{l}\text { Construct lasting } \\
\text { relationships with customers } \\
\text { [6] }\end{array}$ \\
\hline $\begin{array}{l}\text { Obtain knowledge from } \\
\text { customers; and interview } \\
\text { customers [24]. The } \\
\text { significance of customer } \\
\text { knowledge is emphasized } \\
\text { by a number of studies on } \\
\text { KM [24] }\end{array}$ & $\begin{array}{l}\text { Acquiring customers from } \\
\text { various path-ways and the } \\
\text { companies can segment the } \\
\text { customers in accordance } \\
\text { with their core-requirements } \\
\text { and lead them into various } \\
\text { clusters [7] }\end{array}$ \\
\hline $\begin{array}{l}\text { Has a two way } \\
\text { direction [8] }\end{array}$ & Has one way direction [8] \\
\hline Personal medium [8] & Medium is technology [8] \\
\hline $\begin{array}{l}\text { Collect all customer } \\
\text { opinions and } \\
\text { distinguish service } \\
\text { improvement areas } \\
\text { and products } \\
\text { development [8] }\end{array}$ & $\begin{array}{l}\text { The main objective is to } \\
\text { identify profitable } \\
\text { customers and personalize } \\
\text { all marketing activities [8] }\end{array}$ \\
\hline
\end{tabular}

\section{CONCLUSION}

This paper outlined the three stages of change analysis; realization, implementation; monitoring and implementation that are engaged in implementation of CRM in a company. Moreover, it delved the technical facets of CRM and knowledge management and managed to examine KM with CRM favorably and flourishingly. In addition, the value of knowledge on customers and products can deteriorate over time. Since knowledge can get stale fast, the content in a knowledge management program should be constantly updated, rectified and deleted using results from regular survey of customers and Customer Satisfaction Index. In reality, the procedure has been mentioned, which includes some linear and systematic steps, for implementation of CRM in the company. As a result, it was discovered that success 
factors in implementing CRM must consider three components: people, process, and technology which constitute a systemic, integrated and balanced approach followed by a proper comparison, as most of the times there is a misunderstanding between CRM and Knowledge management activities.. In order to achieve this, some factors that assist in the implementation of CRM have been explained such as proper effective integration, CRM software, customer services, organizational behavior change, staff and senior management commitment, managing change, communication and follow-up of employee feedback, effective leadership, managing support, and leadership and training. By contrast, some factors that hinder and cause some issues in the implementation of CRM have been addressed such as lack of holistic approach, outsourcing and lack of ability to deliver the strategy. However, it should be noted that these factors cannot guarantee the success of CRM strategy and they only can evaluate and increase the opportunity of the successful CRM implementation in the organization because each organization has a different background, culture, employee skills, different organizational and functional attitude to IT, organizational size, staff and project management experience. Due to these factors, different approaches and tools would be required, making it impossible to define specific factors for a successful CRM implementation in an organization. In point of fact, the focus of this paper is to indicate that CRM is not merely a technological application in marketing, sales and services, but it is a business strategy that maximizes relationships and embraces the organization. Therefore, it can be concluded that Customer Relationship Management (CRM) implementation is technological-oriented, whereas Knowledge Management [9] implementation is organizational-oriented. However, the implementation of both CRM and KM needs to be matched with the business strategy.

\section{REFERENCES}

[1] R. Bose, "Customer relationship management: key components for IT success," Industrial Management and Data Systems, vol. 102, pp. 89-97, 2002.

[2] R. S. Boulding. W, M. Ehret. W. J. Johnston "A Customer Relationship Management Roadmap: What Is Known, Potential Pitfalls, and Where to Go," Journal of Marketing, vol. 69, pp. 155-166, 2005.

[3] M. Alavi and D. E. Leidner, "Review: Knowledge management and knowledge management systems: Conceptual foundations and research issues," MIS quarterly, vol. 25, pp. 107-136, 2001.

[4] K. Harej, R.V. Horvat, "Customer relationship management momentum for business improvement " Information Technology Interfaces, 2004. 26th International Conference on, vol. 1, pp. 107-111, 2004.

[5] M. D. Homburg. C, D. Totzek, "Customer Prioritization: Does It Pay Off, and How Should It Be
Implemented?," Journal of Marketing vol. 72, pp. 110-130, 2008

[6] M. Gibbert, M. Leibold, and G. Probst, "Five styles of customer knowledge management, and how smart companies use them to create value," European Management Journal, vol. 20, pp. 459-469, 2002.

[7] A. P. Massey, M. M. Montoya-Weiss, and K. Holcom, "Re-engineering the customer relationship: leveraging knowledge assets at IBM," Decision Support Systems, vol. 32, pp. 155-170, 2001.

[8] M. Garcia-Murillo, "Customer knowledge management," The Journal of the Operational Research Society; Houndmills, vol. 53, p. 875, 2002.

[9] K. Bridson, J. Evans, and M. Hickman, "Assessing the relationship between loyalty program attributes, store satisfaction and store loyalty," Journal of Retailing and Consumer Services, vol. 15, pp. 364374, 2008.

[10] Jarman, R. 2008. Benefit Realization. Lecture Notes. 16 September. Curtin University of Technology. Perth.

[11] Jarman, R. 2008. Help Desk. Lecture Notes. 9 October. Curtin University of Technology. Perth.

[12] Jarman, Rodney. Training. Lecture Notes. Curtin University of Technology. Perth.

[13] Kale, S.H. 2004. CRM's Silver Lining. Marketing Management. 10(3): 42-46. Proquest. HYPERLINK "http://proquest.umi.com"http://proquest.umi.com (accessed October 10, 2008)Kennedy, A. 2007. CRM best Practice:Getting it Right First Time at ESB International (ESBI). Irish Journal of Management 11(3): 255-269.

Proquest.HYPERLINK"http://proquest.umi.com" http://proquest.umi.com accessed ctober 10, 2008)

[14] Lee, D., B. Mangen, and B. Thompson 2001. MultiFunction CRM Software: How good is it? $<$ http://www.crmguru.com/crmstudy> (accessed October 10, 2008)

[15] MacSweeney, G. 2000. Hitting the CRM Bullseye. Insurance and Technology: 13(4) 28. Proquest. HYPERLINK "http://proquest.umi.com" http://proquest.umi.com (accessed October 10, 2008).

[16] Massey, A. P., Montoya-Weiss, M. M., \& Holcom, $\mathrm{K}$.

(2001). Re-engineering the customer relationship: leveraging knowledge assets at IBM. Decision

Support Systems, 32(2), 155-170.

[17] Mendoza, A.M. , M. Pérez, and A.C. Grimán. 2006. Critical success factors for customer relationship management. Science Direct. 49(1) : 913-945. Proquest. HYPERLINK "http://proquest.umi.com" http://proquest.umi.com (accessed October 10, 2008) Newell, F. 2000. Customer relationship Management in the New Era of Internet Marketing. Atlanta: MacGraw-Hill, 2000. 
[18] Pass, L. and T. Kuijlen. 2001. Towards a general definition of customer relationship management. Journal Database Marketing10(2):51-60.Proquest. HYPERLINK

"http://proquest.umi.com"http://proquest.umi.com (accessed October 10, 2008)

[19] Pinto, J.K. 1999. Successful Information System Implementation: The Human Side. Perth: PMI.

[20] Rigby, D.K., F.F. Reichheld, and P. Schefter 2002. Avoid the four perils of CRM. Harvard Business Review : 101-109.

Proquest.HYPERLINK"http://proquest.umi.com" http://proquest.umi.com (accessed October 10, 2008)

[21] Robert, T. 2003. Functional silos are a barrier to innovation.

16 Oct. http://www.innovationtools.com/Weblog/innovationb log-detail.asp?ArticleID=284 (accessed October 22, 2008).

[22] Schon, D. A. (1971). Beyond the stable state: public and private learning in a changing society. London (37 Great Russell St., W.C.1), Maurice Temple Smith Ltd.

[23] Stanton, W., R. Buskirk, and R. Spiro. 1995. Management of a Sales Force. Perth: McGraw Hill.

[24] Stefanou, C. J., Sarmaniotis, C., \& Stafyla, A. (2003). CRM and customer-centric knowledge management: an empirical research. Business Process Management Journal, 9(5), 617-634.

[25] Sunassee, N., and A. Sewry. 2002. A Theoretical Framework for Knowledge Management Implementation.Proceedings of SAICSIT 40(4): 111. Proquest. HYPERLINK "http://proquest.umi.com" http://proquest.umi.com (accessed October 12, 2008)Turban, E. T. Aronson and R. Liang. 2006. Decision Support and Business Intelligence Systems. Atlanta: Prentice Hall.

[26] Versleijen, R. 2006. European CRM Services Forecast and Analysis. Tech. Report IDC PR01H. HYPERLINK

"http://proquest.umi.com"http://proquest.umi.com (accessed October 14, 2008)

[27] Winkler, K. and M. Heinz. 2007. Implementation of knowledge management in organization. Springer Science Media5(3)71-81.Proquest.HYPERLINK "http://proquest.umi.com"http://proquest.umi.com (accessed October 10, 2008)

[28] Wu, J. 2007. Customer Relationship Management (CRM).InternationalFederation or Information Processing.225(2):1441-1447.HYPERLINK

ttp://proquest.umi.com"http://proquest.umi.com (accessed October 10, 2008) 